\title{
Letter from the new Editors-in-Chief
}

\author{
Jesús Artalejo • Miguel Angel Goberna
}

Published online: 20 March 2013

(C) Sociedad de Estadística e Investigación Operativa 2013

With this first issue of Volume 21, we start our official appointment as the new Editors-in-Chief of the journal TOP. In 1993, the journal arose out of the transformation of the former journal Trabajos de Investigación Operativa, which was founded by Sixto Ríos in 1950. Thus, the journal is now completing two decades of publications. Thanks to the hard work and efforts of the past editors-in-chief (Jaume Barceló and Laureano Escudero, Ignacio García-Jurado and Marco A. López, Emilio Carrizosa and Justo Puerto), associate editors, authors, referees, and editorial staff, the journal has improved considerably. In particular, the quality of TOP has been strengthened and the journal readership has also experienced a large growth.

We feel that our commitment as editors-in-chief of TOP is to build upon the successes of our predecessors, increasing the journal's relevance and influence worldwide. This will be a huge challenge, given the profusion of similar journals, which are seeking to become a premier publication in the field. To achieve this objective, our aim is to publish high quality papers that contribute to the mathematical issues of Operations Research and its real-world applications.

At this stage of the journal's life, we do not have any other choice, but (i) to extend our gratitude to the Executive Council of the Spanish Society of Statistics and Operations Research (SEIO) and our predecessors, E. Carrizosa and J. Puerto, who relied their confidence in us, (ii) to learn the successful from previous footsteps, and (iii) to enhance the journal's value and reputation.

\footnotetext{
J. Artalejo ( $ه)$

Complutense University of Madrid, Madrid 28040, Spain

e-mail: jesus_artalejo@mat.ucm.es
}

M.A. Goberna

Universidad de Alicante, Alicante 03080, Spain

e-mail: mgoberna@ua.es 
We have started to work, and continue to work hard, to achieve the following targets:

(a) Periodic renovation of the journal Editorial Board, rotating its composition in order to adjust the expertise of its members to the new emerging areas and the current needs of the journal. Moreover, TOP would benefit from the ideas of a new generation of scholars. Many associate editors started to work around July 2012, 6 months before our official appointment. This extra effort is greatly appreciated.

(b) From Volume 21(2) we will keep the tradition of starting each of the three yearly issues with an Invited Paper with Discussion to maintain the journal's visibility and appeal to our readership.

(c) Minimize the delay in publication and push for a rapid turnaround from date of submission. To work along this line, we have decided to stop the publication of special issues starting from Volume 21(2). Springer staff is sending regular reminders to associate editors, referees and authors. Inactive associate editors could be replaced if necessary.

Finally, we are looking forward to a successful outcome. The success of this enterprise depends also on your response. We would appreciate any comments and suggestions you may have to improve the journal.

Jesús Artalejo \& Miguel Angel Goberna

TOP Editors-in-Chief 